\title{
Comparação entre os efeitos da mistura gelatina-resorcina-formaldeído e do N-butil-cianoacrilato em angiorrafias de veia jugular externa de oelhos (Oryctolagus cuniculus) $^{1}$
}

\author{
Cassio Ricardo Auada Ferrigno ${ }^{2}$ \\ Ângelo João Stopiglia ${ }^{3}$ \\ Gervásio Henrique Bechara ${ }^{4}$ \\ Fabio Futema ${ }^{5}$
}

\begin{abstract}
Ferrigno CRA, Stopiglia AJ, Bechara GH, Futema F. Comparação entre os efeitos da mistura gelatinaresorcina-formaldeído e do N-butil-cianoacrilato em angiorrafias de veia jugular externa de coelhos (Oryctolagus cuniculus). Acta Cir Bras [serial online] 2003 Maio-Jun;18(2). Disponível em URL: http://www.scielo.br/acb.
\end{abstract}

RESUMO - Objetivo: Estudar comparativamente os efeitos de dois adesivos cirúrgicos adjutórios à técnica clássica de venorrafia, Colagel ${ }^{\circledR}$ e Histoacryl ${ }^{\circledR}$ no reforço da linha de sutura. Métodos: Os procedimentos, conduzidos em 18 leporinos da raça Nova Zelândia, buscaram investigar a cicatrização de venorrafias pela evolução clínica dos animais, bem como a evolução da cicatrização das feridas cirúrgicas, macroscópica e microscopicamente. Resultados: Os resultados obtidos mostraram, clínica e macroscopicamente, alterações de maior significado e, microscopicamente, predomínio de maior reação inflamatória nas suturas recobertas pelo Colagel ${ }^{\circledR}$, comparativamente às mantidas como controle e às "protegidas" pelo Histoacryl ${ }^{\circledR}$. Conclusões: Houve retardo na cicatrização das feridas que receberam o Colage $^{\circledR}$ e similitude de resultados entre o grupo controle e as suturas recobertas pelo Histoacryl ${ }^{\circledR}$.

DESCRITORES - Venorrafias. Coelhos. Cianoacrilato. Adesivos cirúrgicos.

\section{Introdução}

Nas intervenções cirúrgicas em veias, sejam por trauma ou em procedimentos eletivos, vazamentos e estenoses são ocorrências comuns, causadas principalmente por sua parede fina e sua camada muscular pouco desenvolvida. Por conseguinte, vários autores preconizaram métodos adjutórios à técnica de reparação com adesivos de diferentes substâncias ${ }^{1,2}$.

Os adesivos cirúrgicos são usualmente polímeros constituídos por processo de adição ou condensação simples e compostos que possuem pesos moleculares pequenos, conhecidos como monômeros ${ }^{3}$.

$\mathrm{O}$ adesivo à base de gelatina, resorcina e formaldeído (GRF) é formado por duas partes: uma viscosa (gelatina) e outra líquida (polimerizante), e possui as características de polimerização em aproximadamente dois minutos. Além de flexibilidade, baixa toxicidade, após polimerizado, e biodegradabilidade. Não obstante, possui o inconveniente de baixa transparência e a necessidade do uso do formaldeído livre para a polimerização ${ }^{3}$.

Atualmente, o GRF é largamente utilizado na medicina, como mostra a literatura compulsada, na área de cirurgia vascular, onde atua como adjuvante no tratamento cirúrgico das dissecções aórticas do tipo A, recobrindo a falha entre a parede da aorta e o lúmen desta, endurecendo-o e impedindo ruptura fatal durante o ato cirúrgico ${ }^{4,5,6,7,9}$. Entretanto, outros autores informaram que o GRF causava lesões na parede

\footnotetext{
1 Trabalho do Departamento de Cirurgia da Faculdade de Medicina Veterinária e Zootecnia da Universidade de São Paulo (FMVZ-USP).

2 Prof. Dr. do Departamento de Cirurgia da FMVZ-USP.

3 Prof. Titular do Departamento de Cirurgia da FMVZ-USP.

4 Prof. Titular do Departamento de Patologia da Faculdade de Ciências Agrárias e Veterinárias de Jaboticabal.

5 Prof. Titular do Departamento de Veterinária da Universidade Paulista.
} 
vascular, com grandes extensões de necrose na íntima do vaso e o contra-indicaram nas reparações de vasos, ao contrário da cola de fibrina adesiva que mantinha a arquitetura normal da estrutura? ${ }^{9}$.

Outro tipo de adesivo cirúrgico bastante utilizado são os polímeros a base de cianoacrilato.

Em 1949, foi sintetizado os ésteres alquílicos do ácido cianoacrilato e, 10 anos depois, acidentalmente descobriram o poder de adesão desta substância. Surgiu então a sua primeira denominação comercial, o "Eastman 910 Monomer"10

A polimerização do cianoacrilato provoca o endurecimento dos ésteres ciano-alquílicos, do que decorre sua capacidade adesiva e sua pouca elasticidade. A adesividade aos tecidos se dá por mecanismo aniônico desencadeado pela água ou elétrons livres. Geralmente, a polimerização se completa decorridos 10 a 60 segundos ${ }^{12,13}$.

A reação inflamatória inerente à utilização do adesivo é causada por reações dependentes do oxigênio tecidual ao invés da teoria anterior de reação exotérmica pela polimerização, explicada pela transformação dos ácidos graxos polinsaturados da membrana celular em lipídeos hidroperóxidos, que aumentam o metabolismo do ácido aracdônico local, desencadeando a síntese de tromboxanas e prostaglandina ${ }^{14}$.

No atinente à reparação de vasos, o cianoacrilato mostrou ser promissor no controle de hemorragias nas suturas arteriais ${ }^{15}$.

Como material de síntese de vasos, autores obtiveram bons resultados na reparação de artéria carótida de ratos, onde concluíram que a proposição era segura $^{16}$. Os mesmos resultados foram obtidos em artérias e veias femorais de $\operatorname{ratos}^{17}$.

Não obstante, trabalhos em anastomoses de veias e artérias femorais de cães com o adesivo mostraram excessiva formação de trombos, tendo os autores contra-indicado seu uso ${ }^{18}$.

O objetivo do trabalho foi comparar em veias jugulares de coelhos os efeitos de adesivos a base de cianoacrilato e de gelatina-resorcina-formaldeído em relação ao processo inflamatório.

\section{Métodos}

Foram utilizados 18 animais da espécie leporina, raça Nova Zelândia, hígidos, machos ou fêmeas, adultos. Os animais foram distribuídos em três grupos de seis animais: suturas "protegidas" pela combinação gelatinaresorcina-formaldeído $\left(\right.$ Colagel $\left.^{\mathrm{R}}\right)$ - grupo I; suturas "protegidas" pelo cianoacrilato $\left(\right.$ Hystoacril ${ }^{\mathrm{R}}$ )-grupo II e sutura convencional (não protegida) -grupo III.
Os animais foram submetidos a jejum hídrico e alimentar por quatro horas e anestesiados com solução de $0,1 \mathrm{ml}$ para cada $200 \mathrm{~g}$ de peso corpóreo da diluição Cloridrato de Quetamina ${ }^{1}$ e Cloridrato de Xilazina ${ }^{2}$, em partes iguais, por via intramuscular ${ }^{19}$.

Após tricotomia e preparo rotineiro de campo operatório, junto à face ventral da região do pescoço, foi realizada incisão cutânea de seis cm de comprimento, aplicação dos segundos panos de campo, divulsão dos tecidos subjacentes, localização, isolamento e mobilização da veia jugular externa. Estando o vaso contido sob a apreensão de pinças Bulldog, iniciaramse os procedimentos de diérese mediante o emprego de bisturi, a uma extensão de no máximo $0,5 \mathrm{~cm}$. Findados estes tempos, procedeu-se reparação por meio de suturas em plano único com padrão simples contínuo, com seda 8-0 encastoadas de fábrica, em agulhas atraumáticas ${ }^{20}$. Concluídas as manobras, aplicou-se, no grupo I, sobre as suturas, o adesivo à base de gelatinaresorsina-formaldeído, na forma de fina película, protegendo-se cuidadosamente os tecidos circunjacentes. No grupo II aplicou-se o cianoacrilato à similaridade do anterior. No grupo III, adotado como controle, concebeu-se apenas a aplicação dos pontos de sutura.

Após a sutura da veia procedia-se à retirada das pinças bulldog. Ao verificar-se que não havia vazamento de sangue pela sutura, procedia-se à aproximação da musculatura com náilon 3-0 e a síntese de pele com o mesmo fio.

Analisaram-se os achados relativos as três proposições aos três, 10 e 30 dias de pós-operatório, mediante sacrifício dos animais e avaliação dos fenômenos relativos às características macroscópicas e microscópicas das feridas cirúrgicas, por meio de fotomicroscopia de lâminas coradas com pelo Hemalúmen-eosina.

\section{Resultados}

No estudo macroscópico das lesões, os animais do grupo I apresentaram, aos 30 e 10 dias, reações inflamatórias de grande monta no local de utilização da cola, com aderências de musculatura e estruturas contíguas junto as angiorrafias. Também foi observada nos animais de 30 dias pequena quantidade de substância caseosa próximo às veias operadas. Tais lesões, entretanto, não foram observadas nos animais pertencentes ao mesmo grupo, com período de observação de três dias, em que, as feridas cirúrgicas apresentavam-se sem reação inflamatória aparente, com pouca aderência de estruturas e com a presença da cola bem aderida a angiorrafia. 
Nos animais do grupo II, em todos os tempos de observação, não houve sinais macroscópicos de reação inflamatória, e o adesivo se mostrou bem aderido ao vaso em todos os tempos. Observaram-se nestes casos aderências significativas de musculatura no sítio de emprego do adesivo.

O mesmo observou-se para o grupo III, apenas sendo as aderências de menor monta em relação ao grupo II.

Aos três dias de observação, no grupo I, foi verificada a presença de coágulos aderidos ao endotélio vascular, com infiltrado inflamatório mononuclear moderado, principalmente de linfócitos, hemorragias em tecido adiposo adjacente ao vaso, aliás, que foram observância comum a todos os campos pesquisados (Figuras 1A e B).

Notável reação inflamatória, tecido necrótico ao redor do fio de síntese, no tecido perivascular, ainda solução de continuidade na parede do vaso, com coágulos apresentando pigmentação hemorrágica, e polimorfonucleares neutrófilos e eosinófilos no endotélio lesado, e no espaço perivascular foram observações pertinentes ao grupo II, com três dias de avaliação (Figuras 1C e D) .

Os animais controle (grupo III) manifestaram hemorragias extra vasculares, com presença de eosinófilos, macrófagos e fibroblastos em permeio ao endotélio e adventícia da veia (Figuras 1E e F).
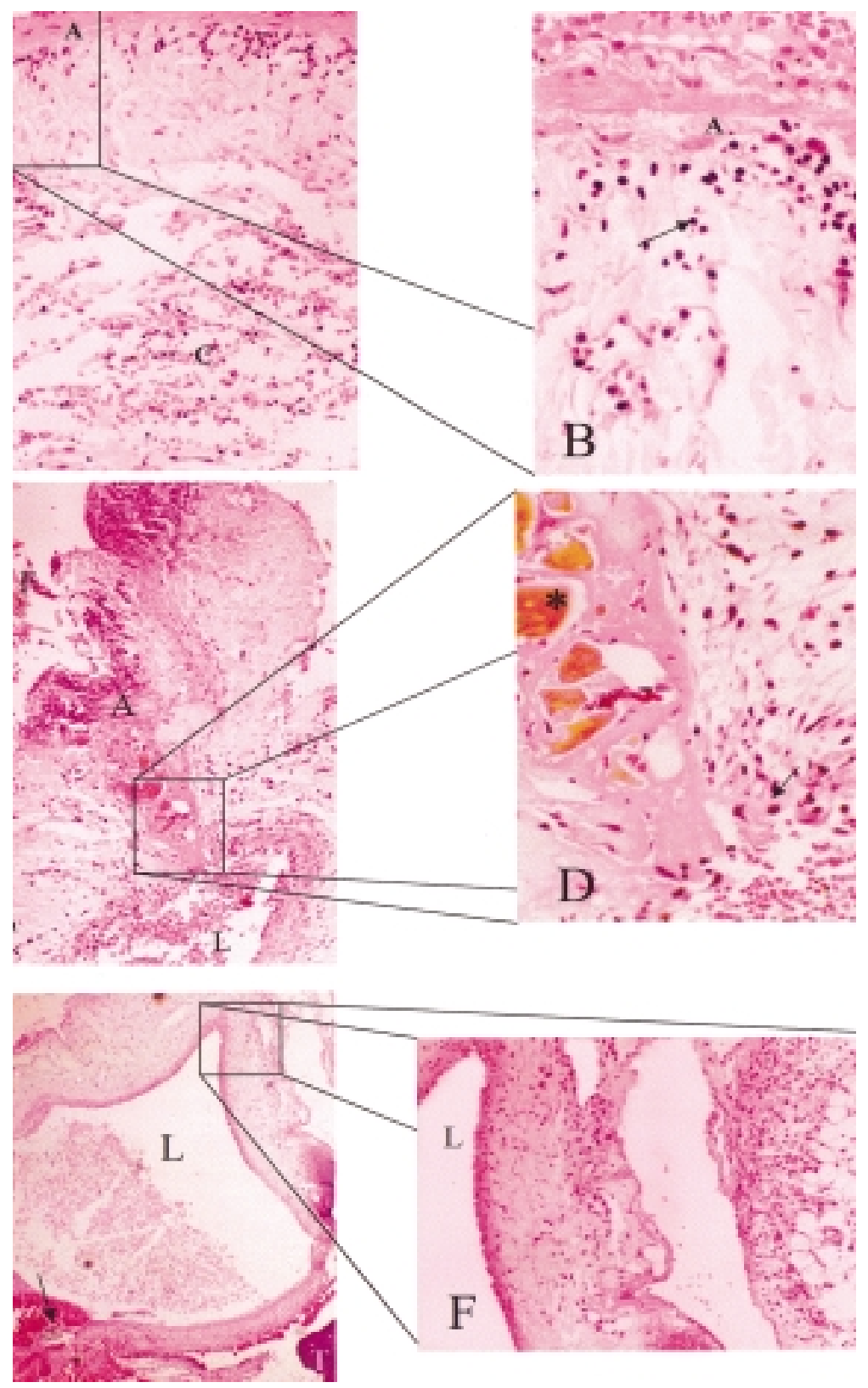

FIGURA 1 - Fotomicrografia de veia jugular externa de coelho, três dias após a venorrafia.

A - Colagel ${ }^{\circledR}$ - Coagulo aderido ao endotélio vascular, e infiltrado inflamatório moderado na adventícia. $\mathrm{A}=$ adventícia, $\mathrm{C}=$ coagulo $\mathrm{H}$.E. (Obj.20x)

B - Colagel ${ }^{\circledR}$ - Pormenor da figura anterior mostrando detalhe das células inflamatórias mononucleares. $\mathrm{A}=$ adventícia, Seta $=$ células inflamatórias mononucleares. H.E. (Obj.40x).

C - Histoacryl ${ }^{\circledR}$ - Notável reação inflamatória e tecido necrótico ao redor do fio de sutura $(\mathrm{F})$. Ainda a figura mostra solução de continuidade na parede do vaso (setas), com presença de pigmentação hemorrágica e polimorfonucleares neutrófilos e eosinófilos marginando o endotélio lesado (e), na adventícia(A) e no espaço perivascular. H.E. (Obj.4x)

D - Histoacryl ${ }^{\circledast}$ - Detalhe da figura anterior, mostrando células inflamatórias polimorfonucleares(seta) e fragmentos do adesivo (*). H.E. (Obj.40x)

E-Controle-Presença de solução de continuidade na parede da veia, com pouca reação inflamatória, e hemorragia. Seta $=$ fio de sutura, $\mathrm{L}=$ lúmen do vaso, $\mathrm{T}=$ cartilagens da traquéia. H.E. (Obj. 4x)

$\mathrm{F}$-Controle - detalhe da figura anterior, mostrando sinais de inflamação em região de tecido adiposo adjacente ao vaso. $\mathrm{L}=$ lúmen do vaso. H.E. (Obj. 10x) 
Aos 10 dias de observação, o grupo I (Colagel) apresentou infiltrado moderado de polimorfonucleares neutrófilos junto às túnicas muscular e adventícia (Figura 2A).

No mesmo período foram observados, no grupo II, proliferação de neovasos, com fibroplasia na adventícia e muscular da veia; constatou-se a presença de células inflamatórias, mononucleares, eosinófilos e células gigantes, principalmente em permeio a fragmentos da cola, aderidos à musculatura da estrutura (Figuras 2B e C).

Os mesmos achados foram reportados no grupo III, menos quanto à reação inflamatória, que foi de menor intensidade, quando comparada ao grupo II (Figuras 2D e E).

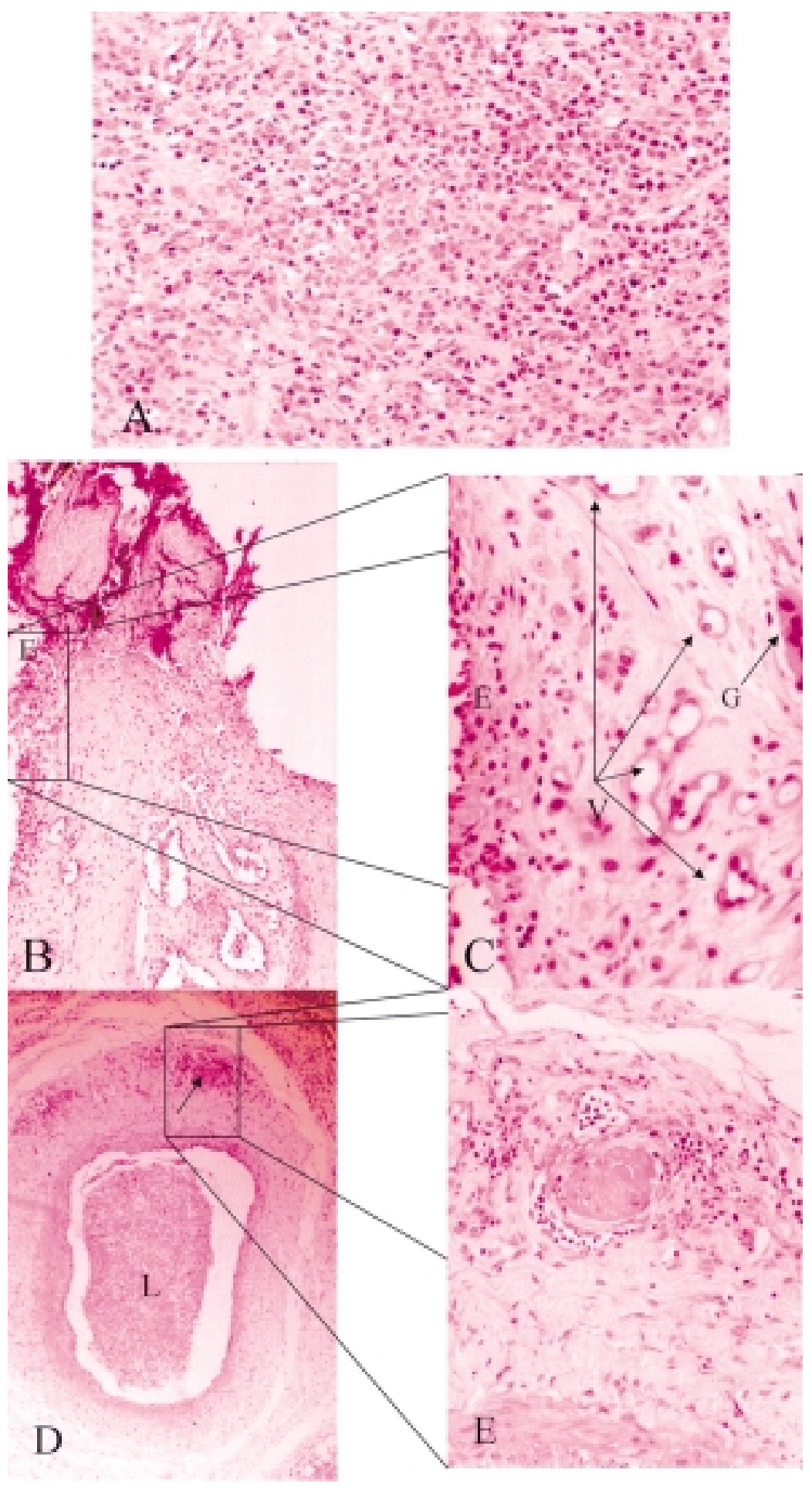

FIGURA 2 - Fotomicrografia de veia jugular externa de coelho, 10 dias após a venorrafia.

A - Colagel $^{\circledR}$ - Infiltrado inflamatório com intensa presença de polimorfonucleares H.E. (Obj.20x)

B - Histoacryl ${ }^{\circledast}$ - Apresentação de tecido cicatricial, com proliferação de neovasos e fibroplasia em região do endotélio vascular ainda nota-se pouca reação inflamatória com células mononucleares, endotélio vascular = E. H.E. (Obj. 4x)

C - Histoacryl ${ }^{\circledR}$ - Detalhe da figura anterior mostrando vasos neo formados (V), fibroplasia e uma célula gigante $(\mathrm{G})$. Endotélio vascular (E). H.E. (Obj. 40x)

D - Controle - Fotografia mostrando parede da veia com granuloma de corpo estranho. No espaço perivascular nota-se presença de infiltrado inflamatório e proliferação de tecido conjuntivo, colágeno e vasos neo formados. Seta = Granuloma corpo estranho, $\mathrm{L}=$ lúmen do vaso. H.E. (Obj. 4x)

E - Controle - Detalhe da figura anterior, mostrando granuloma do tipo corpo estranho envolvido por células inflamatórias mononucleares. H.E. (Obj. 40x) 
Notou-se no grupo I, aos 30 dias, exsudato inflamatório de grande monta com espessamento da parede do vaso, presença predominante de células gigantes, macrófagos, eosinófilos e neovasos com células inflamatórias em seu interior; ainda, alguns sítios de fibroplasia foram encontrados com infiltrado inflamatório (Figuras 3A e B).
No mesmo período de observação, os grupos II e III mostraram-se semelhantes, denotando processo cicatricial completo, com fibroplasia da ferida, e em alguns campos foram notados granulomas de corpo estranho, ao redor do fio de sutura, com células gigantes presentes (Figuras 3C, D e E).
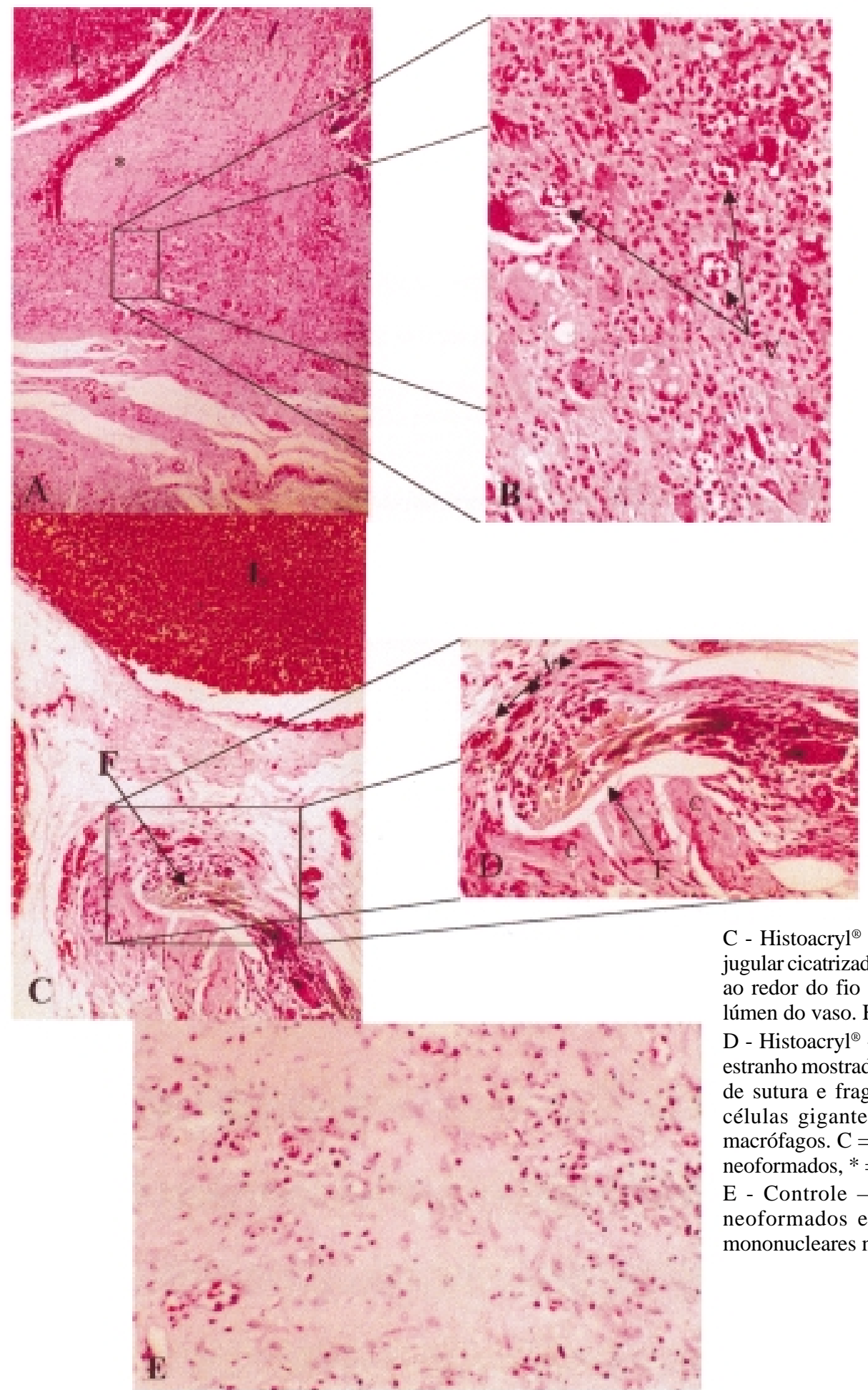

C - Histoacryl ${ }^{\circledR}$ - Apresentação da parede da veia jugular cicatrizada com granuloma de corpo estranho ao redor do fio de sutura. $\mathrm{F}=$ Fio de sutura, $\mathrm{L}=$ lúmen do vaso. H.E. (Obj. 4x)

D - Histoacryl ${ }^{\circledR}$ - Detalhe do granuloma por corpo estranho mostrado na figura anterior, ao redor do fio de sutura e fragmentos de cola, marginados por células gigantes, vasos neoformados e poucos macrófagos. $\mathrm{C}=$ cola, $\mathrm{F}=$ fio de sutura, $\mathrm{V}=$ vasos neoformados, * = células gigantes. H.E. (Obj. 40x) E - Controle - Reação cicatricial, com vasos neoformados e algumas células inflamatórias mononucleares na parede do vaso. H.E. (Obj. 20x) 


\section{Discussão}

O estudo macro e microscópico mostrou, nos indivíduos do Grupo I, reação tecidual de grande significado, principalmente aos 10 e 30 dias de pósoperatório. Estes resultados provavelmente foram provocados por substância irritativa aos tecidos, no caso o formaldeído ${ }^{3}$.

Observações semelhantes foram citadas por outros autores que fizeram estudos experimentais do adesivo ${ }^{10}$.

Em contrapartida, outros trabalhos informaram sobre a utilização do GRF com êxito em intervenções cirurgicas vasculares ${ }^{4,5,6,7,10}$. Há de se notar que a maioria dos trabalhos foram conduzidos em artérias de grosso calibre, onde, provavelmente, as paredes mais robustas, com mais musculatura, não apresentaram problemas de inflamação, principalmente no que tange à estenose. Também a maioria dos trabalhos não cotejou o estudo histopatológico, pois foram realizados em pacientes humanos, o que inviabilizava a coleta de tecidos.

Nos animais do grupo I, o quadro reacional mais incidente aos 10 e 30 dias de observação caracterizouse pela similitude de fenômenos já descritos por outros autores, cujas causas são fruto de condições explicáveis pela dificuldade no monitoramento da aplicação do formaldeído.

Encontrou-se grande dificuldade na aplicação do polimerizante com conta-gotas, como é proposto em sua embalagem comercial, pois o aplicador permite evasão de grande quantidade de formaldeído. A título de possibilitar melhor adequação do formaldeído sobre os tecidos, concebeu-se substituir o conta-gotas por seringa estéril de insulina, agulhada. Com a medida, a instilação foi mais precisa e os efeitos tóxicos, provavelmente, menos significativos.

A reação tecidual determinada pelo Histoacryl ${ }^{\circledR}$, em todos os tempos de observação, mostrou similitude de resultados com grupo controle e, em ambos, o fenômeno fora flagrantemente menos evidenciado quando comparado ao Colagel ${ }^{\circledR}$, mormente aos 10 e 30 dias. Estas constatações permitem admitir tratar-se o cianoacrilato de material relativamente inerte.

As características de material quase inerte, no concernente à cicatrização, foram reportadas no presente trabalho, pois a reação inflamatória apresentada pelo cianoacrilato foi semelhante ao grupo controle em todos os tempos de observação. Resultados análogos foram descritos por vários autores $12,13,14,15,16,17$.

Quanto à adesividade, o cianoacrilato apresentouse de forma estável no decurso dos 30 dias, período máximo de observação ${ }^{12,13}$.
Considerando-se que em suturas vasculares o período crítico não ultrapassaria a quatro dias ${ }^{19}$, tais achados falam em favor de vantagens qualitativas do adesivo.

$\mathrm{Na}$ literatura mundial não se encontrou trabalhos que contemplem a comparação entre os dois adesivos, principalmente em reparação de veias, ficando os resultados de nossa pesquisa como únicos. Mas os trabalhos são claros em mostrar o alto grau de inflamação causado pelos adesivos à base de gelatina-resorcina $\mathrm{e}$ formaldeído, e a pouca reação tecidual do n-2-butilcianoacrilato.,

\section{Conclusões}

1. A mistura Gelatina-Resorcina e Formaldeído $\left(\right.$ Colagel $^{\circledR}$ ) e o N-Butil-2-cianoacrilato (Histoacryl ${ }^{\circledR}$ ) mantiveram sua adesividade por um período de 30 dias.

2. A mistura Gelatina-Resorcina e Formaldeído $\left(\right.$ Colage $\left.^{\circledR}\right)$ proporcionou quadro reacional comparativamente maior ao encontrado com o N-Butil2-cianoacrilato (Histoacryl ${ }^{\circledR}$ ) .

\section{Referências}

1. Nakagawa J, Matsumoto Y, Kawasaki T, Nakayama M, Nishikawa H, Derrick JR. Homotransplantation of the right canine lung. Surgery 1967;61(4):576-83.

2. Kawasaki S, Hashikura Y, Matsunami H, Ikegami T, Nakazawa Y, Watanabe M, Iijima S, Makuuchi M. Temporary shunt between right portal vein and vena cava in living related liver transplantation. J Am Col Surg 1996;183(1):74-6.

3. Grupenmacher F, Adib FC. Estudo experimental do colagel. Novo adesivo biológico em córnea de coelho. An Oftalmol 1990;9:46-50.

4. Matsuda K. Surgery of dissecting aortic aneurysm using GRF glue. Nippon Geka Hokan 1992;61(2):101-2.

5. Weinschelbaun EE, Schamun C, Caramutti V, Tacchi H, Cors J, Favaloro RG. Surgical treatment of acute type A disssecting aneuriysm, with preservation of the native aortic valve and use of biologic glue.Folow up to 6 years. J Thorac Cardiovasc Surg 1992;103(2):369-74.

6. Guilmet D, Bachet J, Goudot B, Dreyfus G, Martinelli GL. Aortic dissection: anatomic types and surgical approaches. J Cardiovasc Surg 1993;34(1):23-32.

7. Borst HG, Bühner B, Laas J. Efficient tissue gluing in aortic dissection. Eur J Cardiothorac Surg 1994;8(3):160-1.

8. Portoghese M, Acar C, Jebara V, Chachques JC, Fontaliran F, Deloche A, Carpentier A. Altérations de la paroi vasculaire dues aux colles chirurgicales: etude expérimental. Presse Med 1992;21(25):1154-6.

9. Coover Junior HW, Joyner FB, Shearer Junior NH, Wicker Junior TH. Chemistry and performance of cyanoacrylate adhesive. Spe J 1959;5:413-7.

10. Cooper CW, Falb R D. Surgical adhesives. Ann New York Acad Sci 1968;146:214-24.

11. Inácio W. Anastomose esôfago-esofágica cervical com o adesivo butil-2-cianoacrilato e em dois planos de sutura com 
fio de algodão: estudo comparativo em cães [Tese - Doutorado]. Faculdade de Ciencias Médicas da Santa Casa de São Paulo; 1983.

12. Tebela GD, Ceriati F, Ceriati E, Vecchioli A, Nori S. The use of cyanoacrilate tissue adhesive in high risk intestinal anastomoses. Surg Today 1995;25(12):1069-72.

13. Giele H. Histoacryl glue as a hemostatic agent in microvascular anastomoses. Plastic Reconstr Surg 1994;94(6):897.

14. Celik H, Caner K, Tahta H, Ozcan OE, Erbengi A, Onol B. Nonsuture closure of arterial defect by vein greft using isobutyl2-cyanoacrylate as a tissue adhesive. J Neurosurg Sci $1991 ; 35(2): 83-7$
15. Middleton WG, Matthews W, Chiasson DA. Histoacryl gluee in microvascular surgery. J Otolaryngol 1991;20(5):363-6.

16. Scheetz WL, Matsumoto T. Cyanoacrylate tissue adhesive: thrombogenic effect. Ann Surg 1970;36(7):418-22.

17. Massone F. Anestesiologia veterinária. Rio de Janeiro: Guanabara; 1988.

18. Palma O. Traumatismo vascular do membro superior [Tese Mestrado].Universidade Federal de São Paulo - Escola Paulista de Medicina; 1990.

19. Litwak P. Principles of vascular surgery. In: Slatter D. Textbook of small animal surgery. 2ed. Philadelphia: W. B. Saunders; 1993. p 890-3.

Ferrigno CRA, Stopiglia AJ, Bechara GH, Futema F. Comparison between the effects of the compound gelatin-resorsin-formaldeide and the N-butil-2-cianoacrilate in the suture of the external jugular veins in rabbits (Oryctolagus cuniculus). Acta Cir Bras [serial online] 2003 May-Jun;18(3). Available from URL: http://www.scielo.br/acb.

ABSTRACT - Purpose: To compare the effects of two surgical adhesives, Colagel ${ }^{\circledR}$ and Histoacryl ${ }^{\circledR}$, coadjutors to the classical vein suture technique, in the reinforcement of the suture line. Methods: The procedures, conducted in 18 rabbits of the New Zealand breed, seeked to investigate the clinical evolution of the animals, as well as the evolution of healing of surgical wounds, macroscopically and microscopically. Results: The results obtained showed, clinical and macroscopically, prevalence of higher inflammatory reaction in the sutures covered by Colagel $^{\circledR}$ compared to the ones maintained as control and protected by Histoacryl ${ }^{\circledR}$. Conclusions: There was healing delay in the surgical wounds that received Colagel ${ }^{\circledR}$ and similar results between the control group and the sutures covered by Histoacryl ${ }^{\circledR}$.

KEY WORDS - Vein suture. Rabbits. Cianoacrylate. Surgical adhesives.

Conflito de interesse: nenhum Fonte de financiamento: nenhuma

Correspondência:

Prof. Dr. Cássio Ricardo Auada Ferrigno

Av. Prof. Orlando Marquez de Paiva, 87

05508-900 São Paulo - SP

Tel.: (11) 3091-1211

cassioaf@terra.com.br

Data do recebimento: $26 / 10 / 2002$

Data da revisão: $12 / 11 / 2002$

Data da aprovação: 05/12/2002 